\title{
POSTERIOR LARYNGEAL CLEFT - ANAESTHETIC EXPERIENCES
}

\author{
M. Yamashita. H.M. Chinyanga and D.J. Steward
}

CONGENITAL POSTERIOR LARYNGEAL CLEFT is a rare congenital anomaly of the airway. The history and the symptoms resemble those of tracheoesophageal fistula, and it should be considered in the differential diagnosis of neonatal respiratory distress aggravated by feeding. Except for one case report ${ }^{\prime}$ this defect has received little attention in the anaesthetic literature.

We present two cases as examples of our anaesthetic experiences in six patients diagnosed as having this defect at The Hospital for Sick Children (H.S.C.). Toronto, between 1968 and 1978. In the two cases the Jako suspension laryngoscope and operating microscope were used and the cleft was sutured by the intraluminal approach.

\section{Case Reports}

Case I

A nine-day-old baby girl was referred from another hospital with a history of recurrent aspiration, respiratory distress, and cyanotic spells during feeding. Barium swallow showed the presence of a laryngeal cleft and this was confirmed by direct laryngoscopy. There were no other congenital abnormalities.

At the age of 17 days the baby was brought to the operating room for direct laryngoscopy and repair of the laryngeal cleft. She weighed $3.7 \mathrm{~kg}$ Temperature was $37^{\circ} \mathrm{C}$ (rectal), respiratory rate was 60 per minute and pulse rate 160 per minute. The haemoglobin was $18.9 \mathrm{gm}$ per cent and urinalysis was normal. The child had been fasted for four hours.

Premedication consisted of atropine $0.1 \mathrm{mg}$ given intramuscularly $\mathbf{4 0}$ minutes before induction of anaesthesia.

M. Yamashita. M.D., Resident, Department of Anaesthesia, The Hospital for Sick Children, University of Toronto. Toronto. Ontario; H.M. Chinyanga, M.D., F.R.C.P. (C), Staff Anaesthetist, The Hospital for Sick Children, University of Toronto, Toronto Ontario; D.J. Steward, M.B. F.R.C.P. (C), Anaesthetist-in-Chief, The Hospital for Sick Children, University of Toronto. Toronto, Ontario.

Requests for Rcprints: Dr. H.M. Chinyanga, Staff Anaesthetist. The Hospital for Sick Children, 555 University Avenue, Toronto, Ontario, Canada. MSG $1 \times 8$.
The temperature of the operating room was raised to $25^{\circ} \mathrm{C}$ and a heating lamp was positioned over the operating table on which a heating pad was placed under a thin blanket.

A precordial stethoscope. blood pressure cuff (left arm), doppler flow probe, adhesive electrocardiogram electrode pads and a rectal temperature probe were positioned. Anaesthesia was induced with nitrous oxide 50 per cent with oxygen, with increasing concentrations of halothane ( $1-1.5$ per cent) and methoxy flurane $(0.5-1.5$ per cent) administered by a face mask and $T$-piece circuit. When the respiratory movements were deep and regular, the laryn $x$ was visualized and sprayed with $10 \mathrm{mg}$ of lidocaine to produce local analgesia. The Jako suspension laryngoscope was then positioned as shown in Figure 1 and anaesthesia was maintained by insuffation of halothane and methoxyflurane in oxygen delivered to the laryngoscope through a side arm. The concentrations of the anaesthetics were continuously adjusted to ensure adequate and regular chest respiratory movements.

With the aid of the operating microscope the surgeon confirmed the diagnosis of posterior laryngeal cleft and proceeded with the repair, using fine silk sutures inserted with microlaryngeal forceps.

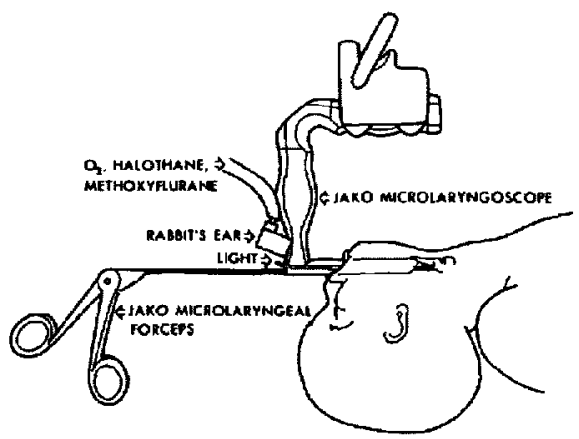

Figure 1 Set up for microlaryngeal surgical repair of posterior laryngeal cleft in children. The JAKO suspension laryngoscope is shown in place with fresh anaesthetic gas inflow and light source ports as well as the JAKO microlaryngeal forceps holding a needle at the distal end.

Canad. Anaesth. Soc. J., vol. 26, no. 6, November 1979 
The patient's vital signs remained stable; systolic blood pressure $60-80$ torr, pulse rate $160-170$ per minute, and rectal temperature $36-36.5^{\circ} \mathrm{C}$. The respiratory rate was between 28-34 per minute. No significant bleeding occurred. At the end of one hour and 40 minutes when the operation was complete the trachea was suctioned by the surgeon and the suspension laryngoscope was removed. A $3.5 \mathrm{~mm}$ clear Portex nasotracheal tube with a straight plastic connector was inserted and secured with a special clip and adhesive tape. ${ }^{2}$ A naesthesia was discontinued and the patient was transferred to the intensive care unit in satisfactory condition. The trachea was extubated on the sixth postoperative day when direct laryngoscopy showed the repair to be intact. Thereafter feeding presented no problems.

At the age of 6.5 weeks when the baby weighed $4.0 \mathrm{~kg}$ there was a recurrence of the original symptoms due to breakdown of the repair. The anaesthetic management for the secondary repair was identical with that described above. The postoperative course was uneventful and the child, now $6 \frac{1}{2}$ years old, has remained asymptomatic.

\section{Case 2}

A male infant was admitted to The Hospital for Sick Children at the age of six days with aspiration pneumonia. Pregnancy and delivery had been normal and the child weighed $2.8 \mathrm{~kg}$ at birth. There had been no respiratory distress immediately after delivery, but the infant coughed and turned blue with his first feeding. This was repeated on subsequent attempts at oral feeding.

The possibility of an H-type tracheoesophageal fistula was raised, and barium swallow was done. This showed inco-ordination of swallowing: the barium flowed down the oesophagus and into the right main bronchus. There was also reflux from the stomach with aspiration into the right lower lobe. Oral feeding was discontinued and total parenteral nutrition commenced.

The baby was nursed in the head up position and a nasogastric tube was inserted and connected to suction. He was referred to the otolaryngology service with a provisional diagnosis of posterior laryngeal cleft. At the age of 3 weeks awake direct laryngoscopy confirmed the diagnosis.

Five days later the infant, then weighing $2.73 \mathrm{~kg}$, underwent operation to repair the cleft. The vital signs were: rectal temperature, $37^{\circ} \mathrm{C}$; respirations, 44 per minute; heart rate, 162 per minute and BP, 88 torr systolic. He was premedicated with atropine $0.1 \mathrm{mg}$ intramuscularly one hour before operation. Following application of a precordial stethoscope. electrocardiograph electrodes and a blood pressure cuff on the left arm. anaesthesia was induced with nitrous oxide oxygen. and increasing concentrations of halothane and methoxyflurane. The larynx and trachea were sprayed with $10 \mathrm{mg}$ of 10 per cent lidocaine. The Jako suspension laryngoscope was inserted and the mixture of nitrous oxide. oxygen, $\left(\mathrm{Fl}_{\mathrm{O}_{2}}\right.$ 0.4-1.0) halothane (1.25-3.0 per cent) and methoxyflurane (1-1.5 per cent) was insufflated. Spontaneous ventilation was allowed but intermittent orotracheal intubation and ventilation of the lungs was done to prevent hypercarbia. With the aid of the operating microscope. the defect between the larynx and oesophagus was closed using interrupted silk sutures. No significant bleeding occurred. Blood pressure, pulse rate and temperature remained stable throughout the procedure. Postoperatively a $3.0 \mathrm{~mm}$ ID clear Portex nasotracheal tube was inserted and secured in place and the patient was transferred to the intensive care unit. The nasotracheal tube was removed six days later and tube feeding was started successfully.

Due to breakdown of the repair and unsuccessful repair on two separate occasions during a period of two months. the laryngeal cleft was finally repaired using a lateral transcervical approach.

The anaesthetic management for this procedure was as follows. The baby, then five months old. weighing $4.22 \mathrm{~kg}$ was fasted for four hours preoperatively. The routine preoperative investigations were normal. After the precordial stethoscope, blood pressure cuff and electrocardiograph electrodes were placed on the patient. atropine, $0.1 \mathrm{mg}$ was given intravenously. The patient was then anaesthetized with a mixture of halothane, methoxyflurane, nitrous oxide, and oxygen through a small mask and a T-piece circuit. The larynx and trachea were sprayed with $20 \mathrm{mg}$ of lidocaine and a \#3.5 Portex thin-walled orotracheal tube was inserted and secured with tape to a bite block. The methoxyflurane was discontinued and anaesthesia was maintained with halothane in nitrous oxide and oxygen delivered through a heated humidifier (Respiratory Equipment Humidifier Series 328). A \#22-gauge cannula was inserted into the saphenous vein at the left ankle and an infusion of 5 per cent dextrose with 0.2 per cent saline commenced at a 
rate of $15 \mathrm{ml}$ per hour. A rectal thermometer probe was used for monitoring body temperature.

A tracheostomy was then done, after which a sterile $4.0 \mathrm{~mm}$ armoured tube was inserted through the stoma, and the tracheal tube was withdrawn. Anaesthesia was continued by this route while the laryngeal cleft was exposed and repaired. There were no problems during operation and the blood loss was $5 \mathrm{ml}$.

At the end of the operation the armoured tube was withdrawn and replaced by a 033 Holinger tracheostomy tube with a Fearon adapter. ${ }^{3}$ Araesthesia was terminated and the patient taken to the intensive care unit in good condition. The duration of anaesthesia was $\mathbf{4}$ hours 25 minutes.

\section{Discussion}

A cleft between the upper respiratory and allimentary tract has been termed posterior laryngeal cleft, laryngotracheoesophageal cleft, or persistent oesophagotrachea according to the extent of the defect. In 1792, Richter reported a possible case of laryngotracheoesophageal cleft. He described an infant in whom palpation with the index finger revealed the gullet and larynx to be a common cavity. No autopsy was performed so this case was not verified. In 1949 Finlay $^{5}$ described the autopsy findings in a patient with posterior laryngeal cleft and awakened interest in this defect. In 1955. Pettersson reported the first successful operation on a newborn with laryngotracheoesophageal cleft. ${ }^{6}$ Evans found 11 cases of the defect over $\mathbf{4 2 7}$ direct laryngoscopies in a five-year period (1969-1974) in children whose presenting symptom was stridor. ${ }^{7}$

This defect is due to an arrest of the cranial advancement of the tracheoesophageal septum or a failure of dorsal fusion of the cartilage centres on each side of the glottis which normally fuse to form the cricoid cartilage. Maternal hydramnios. premature delivery and other congenital malformations are often present. ${ }^{8}$

The chief presenting symptom of the defect is severe choking when oral feeding is attempted causing cyanosis and followed by clinical and radiological evidence of aspiration pneumonia. ${ }^{9}$ The triad of husky cry, feeding difficulty and aspiration pneumonia should alert one to the possibility of this condition. Laryngoscopy by an experienced paediatric endoscopist is essential to confirm the diagnosis. ${ }^{10}$

Preoperatively, these patients should be maintained in the head up position to minimize the danger of aspiration. Many of the reported cases needed tracheostomy and/or gastrostomy. ${ }^{2-15}$ The suggestion that this defect could be repaired at laryngoscopy is a recent advance.

Anaesthesia for microlaryngeal surgery presents several problems. The airway is shared with the surgeon; the surgeon requires adequate space in which to operate and, ideally, unobstructed access to the larynx. The use of a tracheal tube for microsurgery may prejudice these conditions. Manipulations within the airway may cause laryngeal spasm if the topical analgesia and/or the depth of anaesthesia is inadequate. ${ }^{16}$

Our technique relies on inhalational anaesthesia using halothane with supplementary methoxyflurane and topical analgesia with lidocaine. Methoxyflurane depresses the cough reflex to a much greater degree than halothane and produces ideal conditions for operation in the airway. ${ }^{17}$ Clear access to the larynx may be obtained by pharyngeal insufflation of anaesthetic gases during spontaneous ventilation. With this technique gastric distension is not a problem.

Since breakdown of the closure is common. repeated operations may be required, resulting in long periods of hospitalization. ${ }^{13}$

At The Hospital for Sick Children in Toronto. in the 10-year period from 1968 to 1978 , seven cases of posterior laryngeal cleft were diagnosed by the department of otolaryngology. Four of the patients were male. They were between the ages of four days and ten years and weighed between 2.5 and $23 \mathrm{~kg}$. Six patients had problems related to the defect and were operated upon. In three of these, the Jako suspension laryngoscope. operating microscope and Jako microlaryngeal forceps were used and the cleft was repaired by the intraluminal approach. In two of these a successful repair was achicved on the second attempt, the first having broken down. In the third case three attempts failed and the cleft was successfully repaired by the external approach. The other three were repaired by the external approach at the primary operation.

\section{SUMmary}

Two cases of congenital posterior laryngeal cleft are reported which typify the anaesthetic techniques used for operation on this defect at The Hospital for Sick Children, Toronto. Although this anomaly of the airway is rare, it is potentially curable by surgery and should be included in the differential diagnosis of neonatal respiratory distress aggravated by feeding. 
The anaesthetic technique used for microlaryngeal surgery consisted of topical lidocaine, insufflation of oxygen and halothane with supplementary methoxyflurane and spontaneous ventilation. A nasotracheal tube is left in situ postoperatively until laryngeal oedema has subsided. The literature is reviewed and the relevant anaesthetic experience over a ten-year period at The Hospital for Sick Children. Toronto, is summarized.

\section{RÉSUMÉ}

Les auteurs rapportent deux cas de fente laryngée congénitale postérieure et décrivent leur technique anesthésique pour l'intervention corrective de cette anomalie. Bien qu'elle soit rare, cette anomalie peut ètre traitée par la chirurgie et devrait être incluse dans le diagnostic différentiel de la souffrance respiratoire néonatale aggravée par la tétée. La technique anesthésique utilisée comprenait de la lidocaine topique, l'insufflation d'oxygène et d'halothane supplémenté par du méthoxyflurane en ventilation spontanée. Une canule nasotrachéale fut laissée en place jusqu'à ce que l'cedème laryngé soit résorbé. La littèrature est passée en revue et l'expérience pertinente du Toronto Hospital for Sick Children est résumée.

\section{ACKNOWI,EDGEMENTS}

We wish to thank Mrs I. Jaunkalns, the Head Nurse in the E.N.T. Suite, and Mrs M. Casey, the medical artist for their help.

\section{REFERENCES}

I. Ruder, C.B. \& Glaser, L.C. Anesthetic management of laryngotracheosophageal cleft. Anesthesiology 47: 65 (1977).

2. STEWARD, D.J. \& CONN, A.W. A clip to retain and support nasotracheal tubes. Canadian Anaesthetists' Society Journal 15: 397-398 (1968).
3. FEaron, B.. SMITh, C.. Delworla-PaPAdopoulos. M.. Levison. H. \& Swyer. P.R. The idiopathic respiratory distress syndrome in the newborn. Management by tracheostomy and intermittent positive pressure respiration. Annals of Otology. Rhinology and Laryngology 4: 1082 [1964).

4. Richrer, C.F. Dissertatio Medico de Infanticido in Artis Obstetriciae. Thesis. Leipzig (1792).

5. Finlay, H.V.L. Familial congenilal stridor. Arch. Dis. Child. 24: 219 (1949)

6. Petrersson, G. Inhibited separation of the larynx and the upper part of the trachea from the esophagus in a newborn: report of a case successfully operated upon. Acta. Chir. Scand. I0: 250 (1955).

7. Evans, J.N.G. Laryngotracheophsiy. Otolaryngol. Clinics of North America 10:119 (1977)

8. Beazer. R. De Sa, J.D. Freeland, A.P. \& ROBERTSON, N.R.C. Laryngotmcheo-uesophageal cleft. Arch. Dis. Child. 48:912 (1973).

9. Cohen. A.R. Cleft larynx: a report of seven cases. Ann. Otol. Rhinol. Laryngol. 84 : 747 (1975).

10. Pilesbury, H.C. \& Fischier, N.D. Laryngotracheoesophageal cleft: diagnosis, management. and presentation of a new diagnostic device. Arch. Otolaryngol. 103: 735 (1977),

11. Donahol, P.K. \& Hendren, W.H. The surgical management of laryngotracheoesophageal cleft with tracheoesophageal fistula and esophageal atresia. Surgery $7 /: 363$ (1972).

12. Novoselac M. DANGel P. \& Fisch, $V$ Laryngotracheoesophageal cleft. J. Ped. Surg. 8: 963 (1973).

13. Burroughs. N. \& LeAPE, L.L. Laryngotracheoesophageal cleft: report of a case successfully treated and review of the literature. Pediatrics 53 : 516 (1974).

14. PraCy, R. \& Stell., P.M. Laryngeal cleft: diagnosis and management. J. Paryngol. Otol. 88: 483 (1974).

15. Bell, D.W., Christiansen, T.A., Smith. T.E.. JR. \& STUCKER, F.J. Laryngotracheoesophageal cleft: the anterior approach. Ann. Otol. 86: 616 (1977).

16. Lines, V. Anaesthesia for laryngoscopy and microlaryngeal surgery in children. Annesih. Intens. Care $I$ : 507 (1973).

17. Steward, D.J. \& Creighton, R.E. Genemal anesthesia for minor surgery in healthy children. Currem Problems in Anesthesia and Critical Cure Medicine. Year Book Medical Publishers. Inc., Chicago. 1: no. 5(1977). 